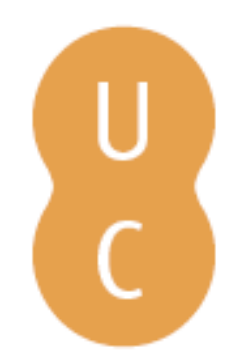

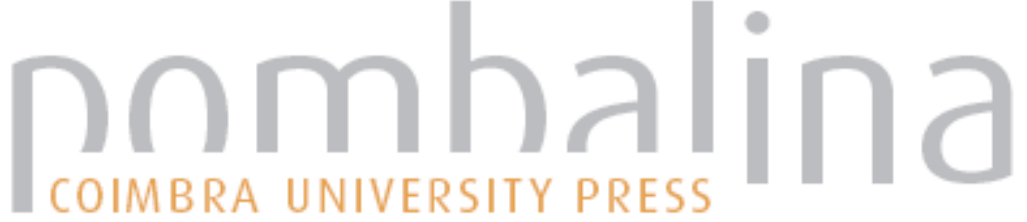

\section{Biografia dos Imperadores em Plínio o Antigo}

\author{
Autor(es): Oliveira, Francisco de
}

Publicado por: Imprensa da Universidade de Coimbra

URL

persistente: URI:http://hdl.handle.net/10316.2/32570

DOI: $\quad$ DOI:http://dx.doi.org/10.14195/978-989-26-0442-8_7

Accessed : $\quad$ 26-Apr-2023 15:01:28

A navegação consulta e descarregamento dos títulos inseridos nas Bibliotecas Digitais UC Digitalis, UC Pombalina e UC Impactum, pressupõem a aceitação plena e sem reservas dos Termos e Condições de Uso destas Bibliotecas Digitais, disponíveis em https://digitalis.uc.pt/pt-pt/termos.

Conforme exposto nos referidos Termos e Condições de Uso, o descarregamento de títulos de acesso restrito requer uma licença válida de autorização devendo o utilizador aceder ao(s) documento(s) a partir de um endereço de IP da instituição detentora da supramencionada licença.

Ao utilizador é apenas permitido o descarregamento para uso pessoal, pelo que o emprego do(s) título(s) descarregado(s) para outro fim, designadamente comercial, carece de autorização do respetivo autor ou editor da obra.

Na medida em que todas as obras da UC Digitalis se encontram protegidas pelo Código do Direito de Autor e Direitos Conexos e demais legislação aplicável, toda a cópia, parcial ou total, deste documento, nos casos em que é legalmente admitida, deverá conter ou fazer-se acompanhar por este aviso.

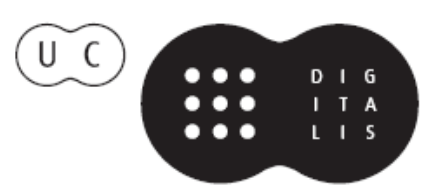


Aurelio Pérez Jiménez, Joșé Ribeiro Ferreira

e Maria do Céu Fialho

(COORdinadores)

\section{Adminiftri Principum.}

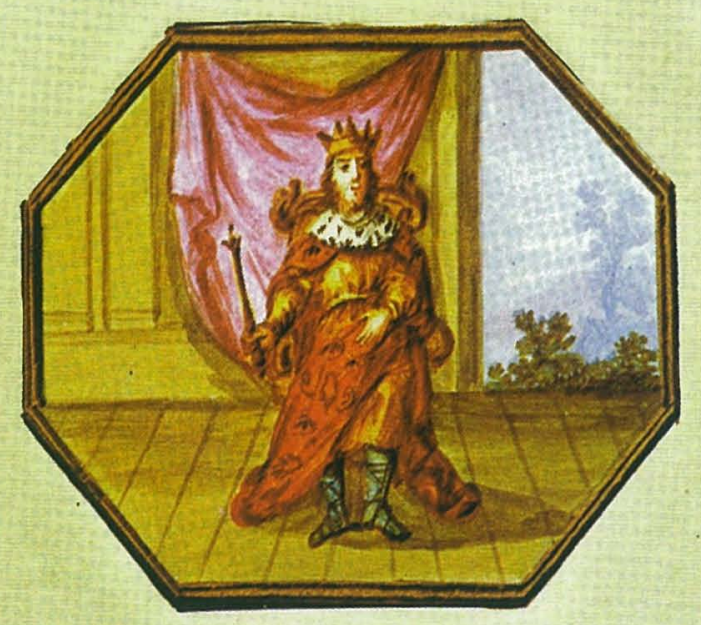

\section{EMBLEM A LIV.}

En tibi plura gerit, quàm lumina prabuit Argos Rex; Aures totidem, quin totidemó, manus. Hec opus Imperio, fidis fupplenda Minijtris, Regi bi funt aures: lumina clara, manus.

\section{- Retrato e a Biografia como estratégia de teorização política}

IMPRENSA DA UNIVERSIDADE DE COIMBRA

Universidad de MálaGa 
(Página deixada propositadamente em branco) 
Aurelio Pérez Jiménez

José RIBEIRo FERREIRA

Maria do Céu Fialho

O RETRATO LITERARIO E A BIOGRAFIA COMO ESTRATÉGIA

\section{DE}

TEORIZACCÃO POLITICA

IMPRENSA DA UNIVERSIDADE DE COIMBRA

UnIVERSIDAD DE MÁlaGa

2004 
Obra publicada com a colaboração de:

Centro de Estudos Clássicos e Humanísticos (Universidade de Coimbra)

International Plutarch Society

Primera edição, Junho de 2004

(c) IMPRENSA DA UnIVERSIDADE DE COIMBRA

(c) Área de Filología Griega. Universidad de Málaga

Coordenação editorial:

Imprensa da Universidade de Coimbra

Área de Filología Griega de la UMA

ISBN: 972-8704-25-9 (PORTUGAL)

ISBN: 84-608-0166-7 (ESPANHA)

Depósito Legal: MA-1420

Impresso em Espanha

Execução gráfica:

IMAGRAF IMPRESORES, S.A.

c/ Nabucco 14

29006 Málaga

Tfno. 952328597

Página de rosto:

"Dos Princepes Transùmptos verdadeiros": Francisco António Novaes Campos, Principe perfeito. Emblemas de D. Joâo de Solórzano. Edição fac-similada do manuscrito da Biblioteca Nacional do Rio de Janeiro oferecido ao Príncipe D. João em 1790 (Prefácio, introdução, comentário e índices por Maria Helena de Teves Costa Ureña Prieto), Instituto de Cultura e Língua Portuguesa, Lisboa, 1985, Emblema LIV, p. 114. 


\title{
Biografia dos Imperadores em Plínio o Antigo
}

\author{
Francisco de Oliveira \\ Universidade de Coimbra
}

\section{Introdução}

A lista das obras de Plínio o Antigo apresentada por Plínio o Moço na Carta 3.5, atribui-lhe três títulos de natureza histórica: De uita Pomponi Secundi duo; Bellorum Germaniae uiginti; A fine Aufidi Bassi triginta duo.

Contudo, o valor do trabalho de Plínio como historiador tem sido avaliado de forma contraditória.

Parece, todavia, seguro admitir que Plínio forneceu informações utilizadas por Díon Cássio, por Suetónio e por Tácito, sobretudo no respeitante às guerras na Germânia ${ }^{1}$.

O seu De uita Pomponi Secundi, atesta o interesse do autor pela biografia.

Por outro lado, um contacto, ainda que breve, com a História Natural, rapidamente evidencia a sua riqueza quanto a informações de valor histórico.

Lorenzo Braccesi interpretou bem este ponto de vista num artigo sobre a dimensão histórica da História Natural. Nele descreveu algumas novidades, desde a importância das fontes epigráficas e monumentais até ser Plínio o "unico fra gli antichi, nel conservarci memoria delle morientes urbium reliquiae o addiritura delle urbes deperditae"2.

1 Plínio é explicitamente citado como fonte em Tac. Ann. I.69 (guerras da Germânia); Suet. Cal. 8; é ignorado em Quint. 10.1.103.

2 Cito L. Braccesi, "Plinio storico", in: Plinio il Vecchio sotto il profilo storico e letterario, Como, p. 72, que se debruça sobre a descriptio Italiae.

A. Pérez Jiménez, J. Ribeiro Ferreira, Maria do Céu Fialho (edd), O retrato literário e a biografia como estratégia de teorização política, Coimbra-Málaga, 2004, pp. 115-130. 
Afigura-se verosímil admitir como hipótese que, na sua enciclopédia, Plínio, utilizou a riquíssima informação histórica que possuía, e que, portanto, a História Natural poderá deixar entrever quais eram os métodos utilizados por Plínio enquanto historiador.

De resto, quanto à utilização de material comum à sua obra histórica, a análise do corpus rapidamente fornece confirmação. Assim, ao referir-se a prodígios prenunciadores do fim de Nero, Plínio utiliza a autocitação, marcada pelas fórmulas sicut in rebus eius exposuimus e sicut in rebus eius rettulimus ${ }^{3}$.

Quanto aos métodos do historiador, a minha investigação limitar-se-á a pesquisar os dados biográficos relativos aos imperadores romanos.

Mas, antes de avançar por essa via, convém estabelecer alguns apontamentos metodológicos prévios:

1. Como julgo ter demonstrado, a noção pliniana de enciclopédia "implica uma selectividade interna e o estabelecimento de critérios que orientam as decisões de selecção ou exclusão e, de igual modo, estabelecem hierarquias e critérios de enumeração dos dados fornecidos"4. Os principais critérios são a brevidade e a utilidade, os quais ditam, naturalmente, a selecção do mais significativo.

Naturalmente que também quanto aos dados biográficos relativos aos imperadores romanos Plínio terá utilizado o mesmo critério, e desde já ouso afirmar que o aplicou na sua obra histórica.

A imagem dos imperadores romanos em Plínio foi já parcialmente tratada sob outras perspectivas. Na minha tese sobre as ideias morais e políticas em Plínio o Antigo, analisei longamente a caracterização dessas figuras com base na influência retórica e na presença da temática diatríbica, que tantos lemas fornecem à invectiva política, e na ideologia do Principado 5 .

Plínio está naturalmente a referir-se à sua obra A fine Aufidi Bassi. Ver, respectivamente Plin. Nat.2.199 (cf.17.245): Non minus mirum ostentum et nostra cognouit aetas anno Neronis principis supremo, sicut in rebus eius exposuimus, pratis oleisque intercedente publica uia in contrarias sedes transgressis in agro Marrucino praediis Vettii Marcelli equitis Romani res Neronis procurantis; e Nat. 2.232: Amnes retro fluere et nostra uidit aetas Neronis principis supremis, sicut in rebus eius rettulimus.

4 Ver "A imagem da Hispânia em Plínio o Antigo", in: Actas do II Congresso Peninsular de História Antiga, Coimbra, 1994, pp. 97-109.

5 F. Oliveira, Les idées politiques et morales de Pline l'Ancien, Coimbra, INIC, 1992. 
Não obstante, ficou por explorar um campo que agora permitirá referendar as minhas conclusões, as quais eram, em essência, as seguintes: omissão de César do número dos imperadores e condenação da sua acção; imagem positiva de Augusto, levemente penalizada por algumas sombras; ambiguidade na caracterização de Tibério, cuja seueritas se agravou com a idade; denegrimento de Cláudio, pela sua lubricidade e pelo seu entourage; condenação total de Calígula e de Nero; imagem negativa de Vitélio; exaltação plena de Vespasiano e de Tito.

2. Desde já se entenderá que, ao admitir a utilização de dados biográficos em obras históricas que não sejam biografias ou uitae, aceito a proposta de Momigliano de relacionar directamente biografia e historiografia ${ }^{6}$.

Em meu entender, a tendência dos historiadores romanos para utilizarem apontamentos biográficos nas suas obras reflecte uma visão moral da história, com consequente valorização das lideranças e personalidades marcantes, cujo retrato, físico e moral, se torna necessário apresentar.

3. A própria retórica fornecia, aos que pretendiam louvar ou vituperar, indicações que orientavam o historiador na utilização de elementos biográficos.

Quintiliano afirma, na Instituição Oratória que a invectiva (uituperatio) utiliza o mesmo tipo de argumentos que o louvor (laus), e que este se socorre dos traços de carácter, do aspecto físico e de outros elementos exteriores ${ }^{7}$.

Descendo a maior especificação, Quintiliano menciona os factos que circundaram o nascimento (oráculos e augúrios) ou a morte.

A. Momigliano, The Development of Greek Biography. Four Lectures, Cambridge Mass., 1971 (trad. esp.: Génesis y desarrollo de la biografia en Grecia, México, Fondo de Cultura Económica, 1986); obra clássica sobre a biografia antiga é a de P. Leo, Die griechisch-römische Biographie nach ihrer literarischen Form, Leipzig, 1901, reimp. Hildesheim, 1965; vide etiam T. A. Dorey, ed., Latin Biography, London, Routledge and K. Paul, 1967; H. Gugel, Studien zur biographischen Technik Suetons, Wien, H. Eöhlaus, 1977; J. A. Sánchez Marín, "Conceptos de biografia en Nepote, Plutarco y Suetonio", Estudos de Filología Latina 31982 211-220; J. Geiger, Cornelius Nepos and Ancient Political Biography, Stuttgart, P. Steiner, 1985; E. Gentili - G. Cerri, Storia e biografia nel pensiero antico, Roma, Laterza (trad. ing.: History and Biography in Ancient Thought, Amsterdam, I. C. Gieben, 1988); K. Meister, Die griechische Geschichtsschreibung, Stuttgart, W. Kohlhammer, 1990; A. Sánchez Marín, Biografia de poetas latinos, Madrid, Ediciones Clásicas, 1991.

7 Quint. Inst.3.19; cf. 3.7.12: Ipsius uero laus hominis ex animo et corpore et extra positis peti debet. 
E, no caso das circunstâncias da morte, levado pela divisão do tempo em antes e depois do homem, tal como referira os augúrios que haviam precedido o nascimento, também agora Quintiliano vai somente ter em consideração o que aconteceu depois da morte. Dá valor, em especial, às obras do espírito (ingeniorum monumenta) deixadas para propagar a memória.

Quanto a virtudes, Quintiliano menciona a fortitudo, a iustitia e a continentia.

Os vícios referidos a propósito da uituperatio são a libido e a luxuria, pelos Romanos considerada o mais grave de todos os vícios ${ }^{8}$.

No seu perspicaz livro sobre Suetónio, A. Wallace-Hadrill escreve que "Plutarch drew on the same groupe of topics as Suetonius: appearance, way of life, physical appetites and cultural interests"".

Como veremos, Plínio precede tanto Plutarco como Suetónio, pois utiliza todos estes pontos de vista.

Quanto à importância dada ao retrato físico da pessoa, a fisiognomonia tem exactamente a função de daí tirar os traços de carácter do indivíduo, de acordo com a própria definição proposta no tratado anónimo que chegou até nós:

$<$ Profitetur $>$ itaque ex qualitate corporis qualitatem se animae considerare atque perspicere.

$<$ Ela intenta $>$ examinar e conhecer a qualidade da alma através das qualidades do corpo ${ }^{10}$.

Em Plínio, a prova mais evidente da utilização da fisiognomonia para traçar o carácter da personagem aparece em relação a Pompeu, em dois passos onde o seu rosto e o seu cabelo são sinais de probitas, seueritas e honor. Transcrevo um desses passos:

Erat et imago Cn. Pompei e margaritis, illa relicino honore grata, illius probi oris uenerandique per cunctas gentes, illa ex margaritis, illa seueritate uicta et ueriore luxuriae triumpho!

Quint. Inst. 3.7.19-20 e 24: ...ueteribus Romanis summum luxuria crimen. Repare-se que crimen aparece como alternativa a uitium. Segundo H. North, Sophrosyne. SelfKnowledge and Self-Restraint in Greek Literature, Ithaca, 1966, e. g. p. 285 sq., para os Romanos a luxuria e a auaritia são os vícios capitais.

A. Wallace-Hadrill, Suetonius, London, Duckworth, 1983, p. 69.

10

Anonyme latin: Traité de physiognomonie, texte établi, traduit et commenté par J. André, Paris, Les Belles Lettres, 1981. 
Havia também um retrato de Pompeu, feito de pérolas, agradável, com a sua madeixa de cabelos penteada para trás e o seu rosto honesto e digno de veneração em todas as nações, com a severidade derrotada e, em boa verdade, mais um triunfo do luxo! ${ }^{11}$

Verificada, pois, a existência de dados fisiognómicos e biográficos, caberá perguntar em que medida e com que intenção Plínio os utilizou para caracterizar os imperadores romanos.

Passo, pois, à análise dos dados da História Natural, que agruparei nos seguintes items: retrato físico; formação e cultura; entourage (expressão mais lata que familia); prodígios, augúrios e mirabilia; vícios e virtudes.

\section{I - Retrato físico}

Além de algumas referências à barba, ao cabelo, à voz e à saúde, a atenção de Plínio fixa-se nos olhos dos imperadores ${ }^{12}$.

Os passos analisados evidenciam que Plínio dá a maior importância aos olhos como elemento descritivo e indiciador do carácter. Ora, se verificarmos o tratado anónimo, lemos exactamente, que os olhos são o essencial da fisiognomonia:

Nunc de oculis disputandum est, ubi summa omnis physiognomoniae constitua est.

Falemos agora dos olhos, ponto essencial de toda a fisiognomonia.

O Naturalista sublinha também a importância dos olhos, quando escreve:

Neque ulla ex parte maiora animi indicia cunctis animalibus, sed homine maxime, id est moderationis, clementiae, misericordiae, odii, amoris, tristitiae ... profecto in oculis animus habitat.

11 Nat. 37.14; cf. 7.53-54: Magno Pompeio Vibius quidam e plebe et Publicius etiam seruitute liberatus indiscreta prope specie fuere similes, illud os probum reddentes ipsumque honorem eximiae frontis.

AUGUSTO - barba: 7.211; olhos: 11.143; saúde: 19.139; 19.128; 22.114; sinete: 37.8; TIBÉRIO - olhos: 11.142-144; cabelo:16.194; saúde: 26.9; CALIGULA - olhos: 11.144; CLÁUDIO - olhos: 11.143-144; NERO - olhos: 11.144; 37.64; rosto: 13.126; cabelo: 37.50; voz: 19.108; 34.166; retrato: 37.118. É interessante comparar estas com idênticas observações de outros historiadores. Assim, sobre a cor dos olhos de Augusto, comparar Nat. 11.143 com Suet. Aug. 79.3 e Phys. 24; sobre os olhos de Tibério, cf. Nat. 11.142144 com Suet. Tib. 68; sobre os de Calígula, cf. Nat. 11.144 com Suet. Cal. 50 e Phys. 22, 31, 32, 33, 35, 79, 105, 106 e 116. Sobre os de Cláudio, Suetónio nada diz; sobre os de Nero, cf. Suet. Nero 51. 
Entre os animais, e sobretudo entre os homens, nenhum outro órgão é melhor espelho da alma - da moderação, da clemência, da misericórdia, do ódio, do amor, da tristeza. É indubitável que a alma habita nos olhos ${ }^{13}$.

No geral, é negativa a imagem dos olhos glaucos (glauci e caesii), como os de Augusto, Tibério e Nero, e dos olhos sanguinolentos, como os de Augusto e Cláudio. Do mesmo modo, de acordo com Phys.22, os olhos fixos, como os de Calígula, são quase sempre malévolos.

Parece, pois, deduzir-se que, no geral, os olhos dos imperadores romanos deixavam transparecer mazelas de carácter, o que é notório na anedota referente a Augusto, que procurava dissimular esse traço característico (11.143):

Diuo Augusto equorum modo glauci fuere superque hominem albicantis magnitudinis, quam ob causam diligentius spectari eos iracunde ferebat.

O divino Augusto tinha os olhos glaucos, como os cavalos, e o branco das pupilas era maior do que o normal. Por essa razão, irritava-se quando alguém atentava neles demoradamente.

\section{II - Formação e Cultura}

De Augusto transparece uma imagem positiva: protege a literatura, expõe pintura, devolve estátuas indevidamente usurpadas ${ }^{14}$.

Tibério revela alguma cultura (humanitas), devolve estátuas aos proprietários legítimos, mas não fomenta o progresso técnico ${ }^{15}$.

Cláudio revela algum interesse pela cultura ${ }^{16}$.

Plin. Nat. 11.145. Cf. Cic. Leg. 1.27: Nam et oculi nimis argute quem ad modum animo affecti simus, loquntur et is qui appellatur uultus, qui nullo in animante esse praeter hominem potest, indicat mores, quoius uim Graeci norunt, nomen omnino non habent. Quanto ao rosto em geral, veja-se Nat. 7.79: Socratem clarum sapientia eodem semper uisum uultu nec aut hilaro magis aut turbato. Exit hic animi tenor aliquando in rigorem quendam toruitatemque naturae duram et inflexibilem affectusque humanos adimit, quales apatheis Graeci uocant...

14 Ver Nat. 3.46; 7.114: Sed et nostrorum gloriam percenseamus ...Diuus Augustus carmina Vergili cremari contra testamenti eius uerecundiam uetuit, maiusque ita uati testimonium contigit quam si ipse sua probauisset; $8.64 ; 34.3 ; 34.43 ; 34.58 ; 35.27 ; 35.94 ; 35.131 ; 36.28$.

15 Nat. 19.145; 35.28 (cf.34.62; 35.70; 35.131): Posuit et Tiberius Caesar, minime comis imperator, in templo ipsius Augusti quas mox indicabimus; 36.195; 36.197.

16

Nat. $7.35 ; 8.65$ (cf. 9.14). 
Nero perverte o gosto artístico e utiliza arte como património individual ${ }^{17}$.

Vespasiano e Tito interessam-se pela cultura, expõem obras de arte, no seguimento das tradições republicanas, e têm apurado gosto artístico ${ }^{18}$.

Verifica-se, pois, que este item inclui um numeroso grupo de apontamentos, nos quais se não encontra a formação do imperador.

Em contrapartida, para além de algumas referências ao labor literário dos imperadores, destaca-se claramente a importância atribuída por Plínio à arte, e à pintura e escultura em especial.

Sobretudo, são positivamente avaliadas as actuações dos imperadores que haviam utilizado a arte para fruição pública e não para deleite privado.

Por razões morais e provavelmente estéticas, é condenada a utilização de materiais caros na produção artística, em especial o ouro, razão pela qual Nero é fortemente censurado.

Destes traços, sobressai, portanto, uma concepção da arte como património colectivo, a qual se terá desenvolvido sobretudo a partir do século I. a.C., quando surgem ou se multiplicam os coleccionadores, restauradores, exposições e museus, e começa a surgir a ideia de património cultural a usufruir por toda a colectividade.

Assim se comprenderão tomadas de posição como as de Plínio o Antigo, quando se insurge contra o luxo decorativo da pintura parietal espalhada pelas villae dos grandes senhores:

Eo uenerabilior antiquitatis prudentia apparet. Non enim parietes excolebant dominis tantum nec domos uno in loco mansuras, quae ex incendiis rapi

Nat. 34.45: (sobre Zenodoro: ....Romam accitus a Nerone, ubi destinatum illius principis simulacro colossum fecit CXIX pedum longitudine, qui dicatus Soli ueneratione est, damnatis sceleribus illius principis; 34.46: Nero gasta ouro e prata em profusão sem conseguir recuperar a arte de fundir o bronze; 34.48: Nero trazia sempre consigo uma Amazona (sobre os bronzes de Corinto, cf.34.82); 35.51: Et nostrae aetatis insaniam in pictura non omittam. Nero princeps iusserat colosseum se pingui $\mathrm{CXX}$ pedum linteo, incognitum ad hoc tempus; 34.82; 34.63: (refere-se a Lisipo: Fecit et Alexandrum Magnum multis operibus, a pueritia eius orsus. Quam statuam inaurari iussit Nero princeps delectatus admodum illa; dein, cum pretio perisset gratia artis, detractum est aurum pretiosiorque talis existimabatur); 34.84: Atque ex omnibus quae rettuli clarissima quaeque in urbe iam sunt dicata a Vespasiano principe in templo Pacis aliisque eius operibus, uiolentia Neronis in urbem conuecta it in selariis domus aureae disposita. Nat. $12.111 ; 34.84 ; 35.120 ; 36.27 ; 36.58 ; 36.102 ; 36.38$. 
non possent. Casa Protogenes contentus erat in hortulo suo; nulla in Apellis tectoriis pictura erat. Nondum libebat parietes totos tinguere; omnium eorum ars urbibus excubabat, pictorque res communis terrarum erat.

Por isso se revela ainda mais venerável a prudência da Antiguidade. Com efeito, não se decoravam então paredes somente para os seus proprietários, nem casas que haveriam de permanecer no seu lugar sem poderem ser salvas dos incêndios. Como casa, Protógenes contentava-se com o seu pequeno jardim. Nenhuma pintura existia nas paredes de Apeles. É que ainda não se cultivava então a moda de pintar completamente as paredes, pois toda a arte era urbana e o pintor era propriedade comum de todos ${ }^{19}$.

Com esta afirmação, Plínio dá voz ao movimento que em Roma, desde a abertura das primeiras bibliotecas e exposições, caminhava no sentido do alargamento dos círculos de cultura e fundava a noção de património cultural.

É essa concepção que preside ao seu julgamento sobre as acções dos imperadores no domínio artístico e permite qualificar como bons governantes aqueles que põem a colectividade acima do seu interesse particular, como é o caso sobretudo de Augusto e de Vespasiano.

\section{III - Entourage}

Augusto é louvado pela pietas e pela familiaritas e prejudicado pela licentia e pela luxuria de Júlia ${ }^{20}$.

Tibério aparece caracterizado pela pietas familiar ${ }^{21}$.

De Calígula só é feita uma breve referência à esposa ${ }^{22}$.

Cláudio, por sua vez, é fortemente penalizado pelas influências femininas, pela potentia consentida aos libertos, tema que se relaciona com a crescente burocratização,

19 Plin. Nat. 35.118, a comparar com Plin. Ep. 3.6.4, onde, depois de recordar a compra de um bronze de Corinto com que se deleita, escreve: Emi autem, non ut haberem domi (neque enim ullum adhuc Corinthium domi habeo), uerum ut in patria nostra celebri loco ponerem, ac potissimum in Iouis templo.

Vide Nat. 2.98 (património familiar); 7.57 (Lívia); 21.9 (filha e genro: Apud nos exemplum licentiae huius non est aliud quam filia diui Augusti, cuius luxuria noctibus coronatum Marsuam litterae illius dei gemunt); 23.58 (Agripa); 36.36 (pietas para com o pai natural); 36.183 (familiaritas para com os amigos).

Nat. 7.84 (pietas para com seu irmão Druso); 10.154 (pietas de sua mãe).

22

Nat. 7.39 
e pela falta de ciuilitas na importante questão das audiências ou admissiones $^{23}$.

Nero é prejudicado por uma mãe criminosa, pela luxuria das esposas, pela riqueza dos servos e libertos, pela luxuria e intemperantia do seu entourage, pela falsa noção de familiaritas e ciuilitas, pela entrega à magia ${ }^{24}$.

Vespasiano e Tito são exaltados pela concordia ou pietas erga parentes, pela familiaritas e pela ciuilitas $^{25}$.

23 Sobre os libertos, vide 9.62 (gula de Optato) e 36.60 (potentia de Calisto); 12.12 (potentia de um liberto de Marcelo Aeserninus); 31.5 (Posídon); 33.134: ...multos postea cognouimus seruitute liberatos opulentiores, pariterque tres Claudii principatu paulo ante Callistum, Pallantem, Narcissum; 33.145: luxo do seu escravo Drusiliano, dispensator da Hispânia Citerior; 35.201: Quos et nos adeo potiri rerum uidimus, ut praetoria quoque ornamenta decerni a senatu iubente Agrippina Claudi Caesaris uideremus tantumque non cum laureatis fascibus remitti illo, unde cretatis pedibus aduenissent; esposa: 10.120 (cf. 10.84); 10.172: Messalina Claudi Caesaris coniunx, regalem hanc existimans palmam, elegit in id certamen nobilissimam e prostitutis ancillam mercennariae stipis eamque nocte ac die superauit quinto atque vicensimo concubitu; 22.92: ...inmenso exemplo in crimen adductos, ueneno Tiberio Claudio principi per hanc occasionem ab coniuge Agrippina dato, quo facto illa terris uenenum alterum sibique ante omnes Neronem suum dedit; 29.8: adultério de Agripina; 33.63: sua luxuria; 35.200-201: sua interferência e ambição política; sucessor (lema da falta de concordia): 36.124: Eiusdem Claudi inter maxime memoranda equidem duxerim, quamuis destitutum successoris odio, montem perfossum ad lacum Fucinum emittendum inenarrabili profecto impendio...

${ }^{24}$ Para a familia em geral, vide 7.58; para a mãe, 7.71; 22.92 (citado na nota anterior); para as esposas: 11.238 (refinamentos da toilette de Popeia); 12.83 (luxo fúnebre); 33.140 (luxo de Popeia); para os escravos e libertos, cf. 18.7 (latifúndios); 35.52; 35.167-168: Patróbio, liberto de Nero, importa areia do Nilo, utilizada ...non ad sustinenda maria fluctusque frangendos, sed ad debellanda corpora palaestrae studiis; para o entourage em geral: 7.129; 28.238 (falsa imagem da popularitas); 29.93; para os vícios de Nero, ver 30.14-15 (magia: quae omnia aetate nostra princeps Nero uana falsaque comperit; quippe non citharae tragicique cantus libido illi maior fuit, fortuna rerum humanarum summa gestiente in profundis animi uitiis, primumque imperare dis concupiuit nec quicquam generosius uoluit. Nemo umquam ulli artium ualidius fauit. Ad hoc non opes ei defuere, non uires, non discentis ingenium, quae non alia patiente mundo! Inmensum, indubitatum exemplum est falsae artis quam dereliquit Nero; utinamque inferos potius et quoscumque de suspicionibus suis deos consuluisset quam lupanaribus atque prostitutis mandasset inquisitiones eas! Nulla profecto sacra, barbari licet ferique ritus, non mitiora quam cogitationes eius fuissent. Saeuius sic nos repleuit umbris; 30.16 e 30.17. Flávios; Praef. 11; 33.41: questão das admissiones. 
Verifica-se, em conclusão, a extraordinária relevância do entourage do imperador, incluindo a mãe, a esposa e os libertos.

O facto tem naturalmente a ver com a realidade insofismável constituída pela consolidação do regime e aparecimento de uma verdadeira corte. Ou, dito de outra maneira: Plínio testemunha a realidade histórica imperial, onde tudo gravita à volta do imperador e da sua família.

Em particular, sobressaem três questões importantes que permitem ajuizar da bondade ou maldade de um imperador: deixar-se dominar pela esposa; permitir aos libertos potentia excessiva; restringir as admissiones.

A questão das admissiones ou audiências, prova suplementar da centralidade da figura do imperador nos tempos que corriam, prenuncia a importância que hão-de assumir as virtudes da familiaritas e da ciuilitas.

Destaca-se, também, um número elevado de referências a Cláudio e a Nero, cujos reinados haviam de ser objecto do A fine Aufidi Bassi.

\section{IV - Prodígios, Augúrios e Mirabilia}

Quanto a Augusto, são favoráveis os prodígios que se lhe reportam. A referência ao Sidus Iulium revela duas características: a dissimulação e a capacidade de condicionamento da opinião pública ${ }^{26}$.

Tibério é caracterizado como supersticioso ${ }^{27}$.

Calígula recebe desfavor de todos os presságios ${ }^{28}$.

Vide Nat. 2.24; 2.93: Cometes in uno totius orbis loco colitur in templo Romae, admodum faustus Diuo Augusto iudicatus ab ipso, qui incipiente eo apparuit ludis, quos faciebat Veneri Genetrici non multo post obitum patris Caesaris in collegio ab eo instituto. Namque his uerbis in <publicum> gaudium prodidit: "Ipsius ludorum meorum diebus sidus crinitum per septem dies in regione caeli sub septemtrionibus est conspectum; id oriebatur circa undecimam horam diei clarumque et omnibus e terris conspicuum fuit. Eo sidere significari uulgus credidit Caesaris animam inter deorum inmortalium numina receptam, quo nomine id insigne simulacro capitis eius, quod mox in foro consecrauimus, adiectum est". Haec ille in publicum; interiore gaudio sibi illum natum seque in eo nasci interpretatus est. Et, si uerum fatemur, salutare id terris fuit; 9.55 (auguria durante a Guerra da Sicília); 11.190; 11.195; 15.136; 33.3.

Nat. $9.10 ; 15.135 ; 16.200$. Os terramotos são considerados por Plínio como presságios geralmente negativos. 
Para Cláudio, os presságios apontados são desfavoráveis ${ }^{29}$.

Quanto a Nero, todos os prodígios são claramente negativos. Qualquer eventual valor positivo é destruído pela ironia ou pelo contexto ${ }^{30}$.

De Vespasiano e os Flávios não há mais que referências anódinas ${ }^{31}$.

Como se vê, neste importante capítulo das biografias ${ }^{32}$, Plínio não recorda augúrios ou prodígios relativos ao nascimento, ao contrário daqueles que precedem ou anunciam a morte.

Compreende-se que, numa óptica política, Plínio tenha preferido assinalar o nascimento político, o que explica o número de augúrios relativos ao surgimento ou incremento do poder dos imperadores.

A relação entre o prodígio e o facto que prenuncia é a relação de igual para igual: isto é, trata-se de identidade de natureza. Serve isto para explicar que o aparecimento do Sidus Iulium só pode ser aceite como salutar através de uma reformulação de conceitos ${ }^{33}$.

Neste caso particular, a transgressão do simbolismo habitual ilustra uma das grandes armas de Augusto: a criação de um sistema global de condicionamento da opinião.

Englobei nesta rubrica determinado número de referências que eram particularmente apreciadas pelo público. A este propósito, escreve Quintiliano:

...sciamus gratiora esse audientibus quae solus quis aut primus aut certe cum paucis fecisse dicetur, si quid praeterea supra spem aut expectationem, praecipue quod aliena potius causa quam sua.

Tenhamos presente que são mais agradáveis aos ouvintes os factos de que se diga ter alguém sido o único ou o primeiro, ou pelo menos um dos poucos a fazê-Ios; ou alguma acção inesperada ou imprevista, sobretudo quando executada mais por causa dos outros do que por sua causa.

Nat. $11.189 ; 16.202 ; 36.70$

30 Ver Nat. 2.92 (cometas); 2.199; 2.232; 4.10; 11.262; 16.233 (luxuria); 16.236; 17.245 (prodígios tirados de árvores, no geral muito funestos).

Ver Nat. 10.120 e 10.139.

32 Veja-se o artigo de J. A. Sanchez Marín, "Prodigios, elementos eróticos y retrato físico en las biografias de poetas", Emerita 53 (1985) 291-308.

33 Sobre as diferenças de ponto de vista, ver Quint. lnst. 3.25. 
Em relação a Nero, dá-se o caso de Plínio referir ter sido ele o primeiro a ser puxado por mulas hermafroditas, facto que, enquanto mirabilia, poderia ser um título de glória pessoal. Todavia, logo Plínio destrói o valor positivo dessa prioridade através da ironia e da sátira:

...quod etiam quadripedum generi accidisse Neronis principatu primum arbitror. Ostentabat certe hermaphroditas subiunctas carpento suo equas, in Treuerico Galliae agro repertas: ceu plane uisenda res esset principem terrarum insidere portentis.

...o que também aconteceu a quadrúpedes, pela primeira vez, segundo creio, no Principado de Nero. É um facto que ele se mostrava no seu carro puxado por mulas hermafroditas, descobertas no campo de Tréveris, na Gália. Coisa bem digna de ser vista, sem dúvida: o príncipe das terras puxado por portentos ${ }^{34}$ !

O mesmo processo de denegrirnento é longamente utilizado para destruir a primazia das residências de Calígula e de Nero em grandeza, riqueza e luxo.

Para que não haja dúvida de que tais imperadores nem a palma da ostentação merecidam, porque dar-lhes uma palma seria conceder-lhes alguma excelência e título de glória, Plínio arranja maneira de a subtrair, e fá-lo com a intenção expressa de os diminuir:

Non patiar istos duos ne hac quidem gloria famae frui docebimusque etiam insaniam eorum uictam priuatis opibus $M$. Scauri ...

Não aceitarei que estes dois gozem sequer da fama deste título de glória e mostrarei que a sua insânia foi ultrapassada pela riqueza privada de M. Scaurus... ${ }^{35}$

\section{V - Vícios e Virtudes}

De Augusto, nada de especial é indicado ${ }^{36}$.

Tibério aparece inclinado ao vinho, intemperante, o que poderá revelar falta de comitas e de ciuilitas, e também supersticioso ${ }^{37}$.

34 Plin. Nat. 11.262.

35 Plin. Nat. 36.113.

36 Ver Nat. 8.155 e 14.61.

37 Nat. 13.94; 14.16; 14.64; 14.144; 14.145; 15.54; 19.64; 19.90; 19.137; 28.23; 34.62 (referência a $O$ homem do estrigilo, de Lisipo:... quem M. Agrippa ante Thermas suas dicauit, mire gratum Tiberio principi. Non quiuit temperare sibi in eo, quamquam imperiosus sui 
Calígula é dado a requintes da moda, à ostentação, à luxuria, à auaritia, à libido e à insania ${ }^{38}$.

Cláudio mostra-se apreciador de jóias, mas o seu maior crime foi a potentia dos libertos ${ }^{39}$.

Nero caracteriza-se por larga panóplia de vícios e designações altamente negativas: luxuria, auaritia, uoluptas, ira, insania, auaritia, odium, uenenum, mors $^{40}$.

inter initia principatus, transtulitque in cubiculum alio signo substituto, cum quidem tanta pop. $R$. contumacia fuit ut theatri clamoribus reponi apoxyomenon flagitauerit princepsque, quamquam adamatum, reposuerit; 37.17: Tolerabiliorem tamen causam fecit C. principis, qui super cetera muliebria soccos induebat e margaritis, aut Neronis principis, qui sceptra <et> personas et cubilia uiatoria unionibus construebat.

Nat. 4.10: quam ob causam perfodere nauigabili alueo angustias eas temptauere Demetrius rex, dictator Caesar, Gaius princeps, Domitius Nero, nefasto, ut omnium exitu patuit, incepto; $5.2 ; 5.11 ; 12.10 ; 13.22-23$ : Vidimus etiam uestigia pedum tingui, quod monstrasse M. Othonem Neroni principi ferebant, quaeso ut qualiter sentiretur iuuaretque ab ea parte corporis? Nec non aliquem e priuatis audiuimus iussisse spargi parites balnearum unguento, atque Gaium principem solia temperari ac, ne principale uideatur hoc bonum, et postea quendam e seruis Neronis ... Ita est nimirum: hac mercede corruptae orbem terrarum deuicere aquilae. Ista patrocinia quaerimus uitiis, ut per hoc ius sub casside unguenta sumantur; 14.64; 16.200; 33.53; 33.79 (Calígula tenta transformar o auripigmento em ouro: Inuitaueratque spes Gaium principem auidissimum auri; quam ob rem iussit excoqui magnum pondus et plane fecit aurum excellens, sed ita parui ponderis, ut detrimentum sentiret propter auaritiam expertus); 35.18 (nu de Atalanta e Helena no templo de Lanúvio: Gaius princeps tollere eas conatus est libidine accensus, si tectorii natura permisisset); 36.111-113: Bis uidimus urbem totam cingi domibus principum Gai et Neronis, huius quidem, ne quid deesset, aurea. Nimirum sic habitauerant illi qui hoc imperium fecere tantum, ad deuincendas gentes triumphosque referendos ab aratro aut foco exeuntes, quorum agri quoque minorem modum optinuere quam sellaria istorum. ...113. Non patiar istos duos ne hac quidem gloria famae frui docebimusque etiam insaniam eorum uictam priuatis opibus $M$. Scauri...

40 Nat. 33.41; 37.85 (jóias).

Nat. 8.196 e 197; 13.22 (refinamentos de toilette); 13.126: (uso de thapsia para melhorar a voz); 17.5:...Neronis principis incendia cultu uirides iuuenesque, ni princeps ille adcelerasset etiam arborum mortem; 18.35 (auaritia: ...latifundia perdidere ltaliam, iam uero et prouincias - sex domini semissem Africae possidebant, cum interfecit eos Nero princeps - non fraudando magnitudine hac quoque sua Cn. Pompeio...; 20.160; 31.40 (uoluptas); 3.47: Nero diminui ratio de ouro nas moedas; 33.164: flutuações de preço no reinado de Nero; 36.111-113 (Domus aurea = insania); 37.17 (refinamentos de toilette); 37.19-20... (luxo na utilização de vasos mírrinos); 37.29 (Nero amissarum rerum nuntio accepto duos calices crystallinos in suprema ira fregit inlisos. Haec fuit ultio saeculum suum punientis, ne quis alius iis biberet). 
De Vespasiano e Tito é exaltada a concordia e a pietas familiar.

Como se vê, recusando teorizar, Plínio não apresenta qualquer catálogo de vícios ou de virtudes imperatoriae. Prefere propor o exemplo negativo e esconjurar o mal pelo processo retórico do exemplo a evitar.

$\mathrm{Na}$ sua invectiva, usa um grupo numeroso de temas da diatribe cínico-estóica, que não é o momento de tratar, recorre à sátira, à ironia e à linguagem metafórica.

Todavia, adivinha-se que o Naturalista tem uma visão clara dos valores que o governante deve cultivar, e, sobretudo, dos vícios e defeitos que ele não deve possuir: auaritia, insania, intemperantia (gula, temulentia, uoluptas), ira, inuidia, libido, luxuria, luxus, ostentatio, saeuitia, seueritas.

O bom govemante será salutaris, enquanto o mau será um uenenum, causador de incendium, mors, odium e potentia.

Ao caracterizar Nero e Calígula como os mais viciosos de entre os imperadores e aqueles que mais prevaricam nos domínios da moral privada, está Plínio a retomar uma linha de orientação que bem conhecemos de Platão, onde o tirano se caracteriza pela sua alma viciosa.

Em suma, pode dizer-se que Plínio é sobretudo um espírito satírico que prefere a invectiva à elaboração teórica de um modelo de governação ideal ${ }^{41}$.

\section{Conclusão}

Em conclusão, parece poder afirmar-se que o Naturalista se socorreu de elementos de natureza biográfica para, por vezes com uma simples pincelada, traçar o retrato dos imperadores romanos, tanto físico como moral, e que esse retrato confirma as conclusões da minha dissertação, com uma ligeira nuance: a imagem de Augusto sai mais penalizada do simples retrato físico do que da generalidade das referências à sua actuação política.

Por outro lado, o recurso a elementos biográficos evidencia, por parte do autor, uma visão moral da história, centrada à volta de personalidades de relevo.

A remissão para a sua própria obra histórica é evidente prova de que, sob o ponto de vista historiográfico, a História Natural tem um significado assinalável.

41 Vide F. Oliveira, Les idées politiques et morales de Pline l'Ancien, Coimbra, INIC, 1992, p.343. 
Em consequência, será lícito concluir que, nos seus momentos de cariz historiográfico, Plínio utilizou técnicas que certamente aplicara na sua obra histórica. Dito por outras palavras: a sua obra histórica recorria certamente a uma grande panóplia de elementos biográficos.

Outro aspecto a considerar é que, nos apontamentos biográficos, Plínio utiliza uma selectividade que prefere recorrer ao essencial e mais significativo e esquecer o secundário.

Também aqui é, pois, de inferir, que, na sua obra história, Plínio utilizaria os mesmos processos gerais de composição que presidem à História Natural: preferir o útil ao agradável, isto é, considerar a história como fonte de ensinamento moral, e ser breve, ou seja, tratar somente o mais importante e o que possa servir esse objectivo. 


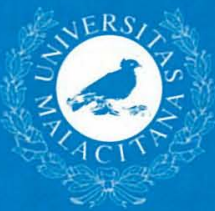

